Wolfgang Ernst

\title{
Rechtserkenntnis durch Richtermehrheiten
}

"group choice« in europäischen Justiztraditionen

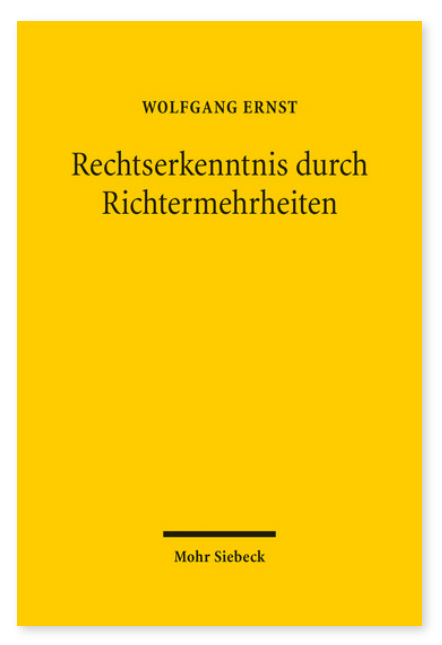

2016. XX, 362 Seiten.

ISBN 978-3-16-154548-1

DOI 10.1628/978-3-16-154548-1

eBook PDF 129,00€

ISBN 978-3-16-154361-6

Leinen $129,00 €$
Wenn mehrere Richter zur Entscheidung desselben Falles berufen sind, verschränkt sich die Aufgabe der normgebundenen Rechtserkenntnis mit der einer kollektiven Entscheidungsfindung (»group choice«). Die resultierenden Schwierigkeiten und Lösungsverfahren werden seit der Antike diskutiert. Unterschiedliche Regelungen in europäischen Justiztraditionen werden dadurch geprägt, ob das Verfahrensergebnis in einem Kollegialakt oder in einer Mehrheit von Einzelerkenntnissen besteht. Abgesehen von Problemen der Mehrheitsbildung bei quantitativen oder qualitativen Divergenzen über den Urteilstenor zwingt die Begründungspflicht zur Findung von zugleich mehrheitsgetragenen wie stimmigen Urteilsgründen. Dies führt auf die Frage, ob die juristische Methode, die Singularmethode ist, nicht einer Erweiterung bedarf, die den Einigungsprozess im Richterkollegium einer nachvollziehbaren Methodik unterwirft.

Wolfgang Ernst ist Regius Professor of Civil Law an der University of Oxford.

Jetzt bestellen:

https://mohrsiebeck.com/buch/rechtserkenntnis-durch-richtermehrheiten-9783161545481?no_cache=1

order@mohrsiebeck.com

Telefon: +49 (0)7071-923-17

Telefax: +49 (0)7071-51104 